\section{FIGURA DO DELEGADO DE POLÍCIA E O PRIMEIRO JUÍZO DA TIPICIDADE PENAL DO FATO.}

\section{THE FIGURE OF THE POLICE DELEGATE AND THE FIRST JUDGMENT OF CRIMINAL TYPICALITY.}

\section{Diego Charles Teixeira Matos ${ }^{1, *} /$ Rodrigo Gonçalves Brito ${ }^{2} /$}

\section{INTRODUÇÃO}

A vida em coletividade é constituída de um conjunto de regras estabelecidas pelo Direito. No entanto, este conjunto seria inútil se não houvessem agentes e órgãos para obter o controle e o objetivo desejado pela lei.

Dentre estes órgãos têm-se as Polícias, que atuam nos mecanismos de controle e prevenção sociais, visando a proteção e a tranquilidade da sociedade como um todo para garantir-lhe a segurança.

Geralmente, o primeiro jurisperito a ter acesso ao fato criminoso é o Delegado de Polícia, ficando assim, responsável pela supervisão da delegacia de sua contenção. É a Autoridade Policial que determina ordens de abertura de inquérito policial, investigações, perícias, bem como outros procedimentos. Tal figura é investida de atribuições e deve agir com cautela frente ao direito fundamental da liberdade da pessoa humana, pois em alguns casos deverá restringir essa liberdade, garantida pela Carta Magna de 1988.

${ }^{1}$ Centro Universitário FG - UNIFG, Guanambi, Bahia - Brasil.

${ }^{2}$ Universidade Estadual de Montes Claros, Minas Gerais - Brasil

*E-mail para correspondência: diegocharllesadv@ @otmail.com

\section{RESUMO}

Geralmente, o primeiro jurisperito a ter acesso ao fato criminoso é o Delegado de Polícia, o qual é investido de atribuições que exigem atuação cautelosa frente ao direito fundamental da liberdade da pessoa humana. Dessa forma, o propósito desta revisão de literatura é refletir sobre a capacidade judicante do Delegado de Polícia no que se refere à possibilidade de aplicação das excludentes de antijuridicidade em virtude do desempenho do seu trabalho, bem como sua atuação na persecução penal, através da metodologia de pesquisa dedutiva. Verificou-se que a doutrina estudiosa do tema não é unânime, pois há corrente que considera tal atribuição vedada à autoridade policial, todavia o estudo evidenciou que é mais acertado o entendimento segundo o qual deve ser atribuída ao delegado de polícia a possibilidade de deliberação acerca da presença ou não de circunstâncias que excluam a ilicitude do fato, isso porque a atual Constituição Federal traduz o retorno do Estado Democrático de Direito, com forte apreço pelo respeito aos direitos humanos, especialmente o direito à liberdade.

Palavras Chave: Direito à Liberdade. Autoridade Policial. Excludente de Antijuridicidade.

\section{ABSTRACT}

Generally, the first jurisdiction to have access to the crime is the Police Delegate, who is vested with assignments that require cautious action against the fundamental right to freedom of the human person. Thus, the purpose of this literature review is to reflect on the judicial capacity of the Chief of Police to judge the possibility of applying the exclusions of antijuridicidad by virtue of the performance of their work, as well as their action in the criminal prosecution, through the methodology deductive research. It was verified that the doctrine studious of the subject is not unanimous, since there is current that considers such attribution prohibited to the police authority, nevertheless, the study showed that it is more correct the understanding according to which the police delegate should be given the possibility of deliberation about the presence or not of circumstances that exclude the illegality of the fact, this because the current Federal Constitution reflects the return of the Democratic State of Law, with a strong appreciation for respect for human rights, especially the right to freedom.

Keywords: Excluding Antijuridicity. Police Authority Right to Freedom.

Submetido em: 03 de mar. 2019

Aceito em: 09 de out. 2019 
À vista disto, o propósito deste artigo é refletir sobre a atuação do Delegado de Polícia no que se refere à possibilidade de aplicação das excludentes de antijuridicidade no desempenho do seu trabalho, bem como sua atuação na persecução penal, mostrando os entendimentos doutrinários acerca do papel do Delegado de Polícia e como seu trabalho influencia na persecução penal. Trata-se, ainda, acerca da Proposta de Emenda à Constituição n ${ }^{\circ}$ 293/2008, que tem o intuito de atribuir a independência funcional ás Autoridades Policias.

A justificativa para discorrer sobre a temática reside, sobretudo, na inquietação de se compreender na sistemática legal brasileira, a real capacidade do Delegado de Polícia e a atividade por ele desempenhada, bem como de que modo é realizada a primeira análise do fato criminoso, por este profissional, com a respectiva tipificação.

Para que os objetivos fossem alcançados, tratou-se sobre função jurídica e a discricionariedade da Autoridade Policial, bem como o contexto histórico do cargo de delegado de polícia. Discutiu-se sobre a possibilidade da aplicação das excludentes de antijuridicidade pela autoridade policial, acrescentando-se vírgulas sobre a independência funcional do Delegado no contexto da proposta de Emenda à Constituição no 293/2008.

A abordagem da pesquisa de estudo foi realizada em subtemas, apresentando um delineamento de ideias e implicações legais e doutrinárias, tratando sobre as atribuições do Delegado de Polícia no âmbito da política criminal.

\section{MATERIAL E MÉTODOS}

Com o intuito de discorrer sobre o tema, realizou-se uma construção teórica, utilizando-se como técnica de pesquisa a revisão bibliográfica que, segundo Lakatos e Marconi (2003), consiste no levantamento da bibliografia publicada sobre a temática em pesquisa, seja em livros, revistas, monografias, teses, dissertações, entre outros, colocando o pesquisador em contato direto com o material escrito sobre $\mathrm{o}$ assunto.

Para que houvesse consonância com todas as nuances do Direito aplicável ao tema, utilizou-se precipuamente a metodologia dedutiva, isto porque a pesquisa empregou a revisão bibliográfica e documental legal por meio da legislação brasileira, jurisprudências, artigos científicos e posições literárias de doutrinadores brasileiros. Este foi o método de procedimento específico do trabalho em questão.

As respectivas análises foram organizadas em relatório de pesquisa componente da construção do estudo pretendido, onde estiveram presentes dados históricos, conceituais e normativos, por meio de pesquisa documental exploratória alusiva ao tema escolhido.

Foram realizadas pesquisas bibliográficas em diversas doutrinas sobre o Direito Penal, Processual Penal, Leis específicas, artigos científicos sobre a temática, monografias e dissertações apresentadas, bem como em revistas sobre a temática.

A coleta de dados seguiu a seguinte ordem: leitura exploratória de todo material optado, consistente na leitura rápida que busca verificar se o material em si é de mérito para o presente trabalho; leitura seletiva, com maior aprofundamento nos elementos de foco da pesquisa; apontamento de elementos extraídos das fontes como ferramenta especifica (métodos, autores, resultados, ano).
A análise e anotação dos resultados foram atingidas por uma leitura sintética com o intento de classificar e sumariar os elementos contidos nas fontes, de forma que estas possibilitassem a obtenção de respostas ao problema da pesquisa.

Desta forma, o trabalho foi estruturado da seguinte maneira: inicialmente, fez-se uma exposição da função jurídica e da discricionariedade jurisperita da autoridade policial, tratando também, brevemente, a respeito do contexto histórico do cargo de Delegado de Polícia. Posteriormente, dissertou-se acerca do tema cerne do trabalho, qual seja, a aplicação das excludentes de antijuridicidade pelo Delegado de Polícia. Ato contínuo, refletiuse sobre a independência funcional do Delegado de Polícia face a proposta de emenda à constituição $n^{\circ}$ 293/2008. Por derradeiro, foram tecidas as considerações finais.

\section{AUTORIDADE POLICIAL: FUNÇÃO JURÍDICA E DISCRI- CIONARIEDADE JURISPERITA}

Por meio da Portaria de 04 de novembro de 1825 é que se deu origem à figura dos Delegados de Polícia, em que estes eram introduzidos na Corporação de Comissários de Polícia, não havendo assim a carreira de Delegado de Polícia, propriamente dita. O posto era conferido a essa equipe de confiança, cujo titular era nomeado por indicação política (CAMARGO, 2015).

Deste modo, cumpre salientar que só poderiam ser nomeados pessoas marcadas pela honra, integridade, retidão e idolatria à pátria. Os Comissários de Polícia tinham como atribuições, entre outras, a chefia das repartições da Polícia da Corte e a realização de averiguações (CAMARGO, 2015). 
Em 1828, foi extinta a atividade dos Comissários de Polícia, cujos cargos policiais foram unificados aos Juízes de paz que adaptaram a abranger os respectivos papéis policiais materializados na Carta de 26 de outubro de 1829 . Entre o período de 1820 a 1840, os Juízes de paz cada vez ganhavam mais força, principalmente, regulados pela ascensão dos liberais no poder (CAMARGO, 2015).

No entanto, no ano de 1841 , os juízes de paz, perderam suas atribuições policiais, sendo criadas as funções de Delegado de Polícia e Subdelegados, por meio da Lei $\mathrm{n}^{\mathrm{o}} 261$ de 1841 , regulada pelo Decreto $n^{\circ} 120$, de 31 de janeiro de 1842.

Atualmente, o Delegado de Polícia é investido, por força de disposição constitucional (artigo 144, $\$ 4^{\circ}$ ) e por disposição legal (artigos $4^{\circ}$ e $5^{\circ}$ do Código de Processo Penal), na atribuição de investigar privativamente os ilícitos penais praticados e sua autoria.

Cabe ao Delegado de Polícia a primeira análise dos fatos apresentados. Não pode ele agir como um mero escriturário e tratar os atos de privação de liberdade como mera rotina a ser realizada (ALMEIDA, 2015).

As atribuições de Polícia Judiciária que são desempenhadas pelo Delegado de Polícia têm amparo na Constituição Federal e na Lei $n^{\circ}$ 12.830, de 20 de junho de 2013, entendendo que essas atribuições são de gênero jurídico, indispensáveis e exclusivas do Estado, e que a carreira de Delegado de Polícia é absolutamente recaída de juridicidade.

$\mathrm{O}$ artigo $2^{\circ}$ da Lei 12.830/13 veio para extinguir a antiga ideia de que a profissão de Delegado de Polícia não compreendia a característica jurídica:

Neste significado:
Art. $2^{\circ}$ As funções de polícia judiciária e a apuração de infrações penais exercidas pelo Delegado de Polícia são de natureza jurídica, essenciais e exclusivas de Estado (...)

$\S 1$ o Ao delegado de polícia, na qualidade de Autoridade Policial, cabe a condução da investigação criminal por meio de inquérito policial ou outro procedimento previsto em lei, que tem como objetivo a apuração das circunstâncias, da materialidade e da autoria das infrações penais (BRASIL, 2013).

Portanto, pelo trecho acima exposto, evidencia-se que a atuação da Autoridade Policial possui natureza jurídica, não apenas administrativa, como era anteriormente visualizada. Ademais, a referida função é dotada de essencialidade para o Estado, bem como é exclusiva deste.

Outrossim, a Lei $n^{\circ} 11.113$, de 13 de maio de 2005 deu nova redação ao caput do art. 304 do Código de Processo Penal, o qual exemplifica a atuação jurídica do Delegado de Polícia.

O mencionado dispositivo vigora com o seguinte teor:

Art. 304. Apresentado o preso à autoridade competente, ouvirá está o condutor e colherá, desde logo, sua assinatura, entregando a este cópia do termo e recibo de entrega do preso. Em seguida, procederá à oitiva das testemunhas que o acompanharem e ao interrogatório do acusado sobre a imputação que lhe é feita, colhendo, após cada oitiva suas respectivas assinaturas, lavrando, a autoridade, afinal, o auto.

Sendo assim, a Autoridade Policial deverá admitir a análise jurídica atinente aos fatos descritos com o intuito de se determinar sobre o destino do presumido transgressor.

Silva (1992) ampara que a pertinência desempenhada pelos Delega- dos de Polícia é jurídica pelas seguintes razões:

Todas elas são carreiras jurídicas, primeiro porque exigem formação jurídica como requisito essencial para que nelas alguém possa ingressar; segundo porque todas têm o mesmo objeto, qual seja: a aplicação da norma jurídica; terceiro porque, por isso mesmo, sua atividade é essencialmente idêntica, qual seja, a do exame de situações fáticas específicas, emergentes, que requeiram a solução concreta em face da norma jurídica, na busca de seu enquadramento nesta, o que significa a subsunção das situações de fato na descrição normativa, operação que envolve interpretação e aplicação jurídica, campo essencial comum que dá o conceito dessas carreiras (SILVA, 1992, p. 507).

Assim, no campo da persecução penal é o Delegado de Polícia o primeiro a deliberar com relação aos pedidos de limitação a normas fundamentais, contudo, não é aquele que se contenta sem examinar estruturas legais e se mantém afastado à criminologia que lhe rodeia.

No que diz respeito a esse poder discricionário, ressalva Meirelles:

Tanto nos atos vinculados como nos que resultam da faculdade discricionária do Poder Público, o administrador terá de decidir sobre a conveniência de sua prática, escolhendo a melhor oportunidade e atendendo a todas as circunstâncias que conduzam a atividade administrativa ao seu verdadeiro e único objetivo - o bem comum (MEIRELLES, 1993, p. 143/144).

A Autoridade Policial tem diversas atribuições, dentre elas a de avaliar a probabilidade legal e jurídica 
daquilo que foi exposto na Ocorrência Policial lavrada pelo ofendido, com base no princípio da motivação.

Nesse trilhar, enfatiza Mirabete:

Ao receber o preso e as notícias a respeito do fato tido como criminoso, a autoridade policial deverá analisar estes e os elementos que colheu com muita cautela, a fim de verificar se é hipótese de lavrar o auto de prisão em flagrante. A prisão não implica obrigatoriamente na lavratura do auto, podendo a autoridade policial, por não estar convencida da existência de infração penal ou por entender que não houve situação de flagrância, conforme for a hipótese, dispensar a lavratura do auto, determinar a instauração de inquérito policial para apurar o fato, apenas registrá-lo em boletim de ocorrência etc., providenciando então a soltura do preso (MIRABETE, 2005, p. 288).

Ainda nessa perspectiva, Pereira aponta que:

O Delegado de Polícia pode e deve relaxar a prisão em flagrante, com fulcro no art. 304, § $1^{\circ}$, interpretado a "contrario sensu", correspondente ao primeiro contraste de legalidade obrigatório, quando não estiverem presentes algumas condições somente passíveis de verificação ao final da formalização do auto, como, por exemplo, o convencimento, pela prova testemunhal colhida, de que o preso não é o autor do delito, ou, ainda, quando chega à conclusão que o fato é atípico (PEREIRA, 1980, p. 233-234).

Os Delegados de Polícia são confiados de conhecimentos jurídicos e estes conhecimentos precisam ser bem considerados, já que imunizam contra acumulações desnecessárias de Inquéritos Policiais e Termos Circunstanciados de Ocorrência em juízo, assim como oferecem os mesmos auxí- lios para abranger os idênticos propósitos dos Defensores Públicos, Promotores de Justiça e Juízes de Direito: a segurança jurídica, o êxito da Justiça, a harmonia dos princípios constitucionais e o democratismo pleno (CAMARGO, 2015).

\section{APLICAÇÃO DAS EXCLUDEN- TES DE ANTIJURIDICIDADE PELO DELEGADO DE POLÍCIA}

A atual sistemática legal atribui exclusivamente ao juiz togado a competência para análise e aplicação das excludentes da antijuridicidade do fato, bem como do princípio da insignificância. É o que se extrai da leitura do artigo 310 do Código de Processo Penal, in verbis:

Art.310. Ao receber o auto de prisão em flagrante o juiz deverá fundamentadamente:

I-relaxar a prisão em flagrante; ou

II- concederá prisão em flagrante em preventiva, quando presentes os requisitos constantes no art.312 desde Código, e se revelarem inadequadas ou insuficientes as medidas cautelares diversas da prisão; ou

III- conceder liberdade provisória com ou sem fiança.

Parágrafo único. Se o juiz verificar, pelo auto de prisão em flagrante, que o agente praticou o fato nas condições constantes dos incisos I a III do caput do art. 23 do Decreto-Lei no 2.848, de 7 de dezembro de 1940 Código Penal, poderá, fundamentadamente, conceder ao acusado liberdade provisória, mediante termo de comparecimento a todos os atos processuais, sob pena de revogação (BRASIL, 1941).

Tal disposição legal gera dúvidas quanto à possibilidade de a autoridade policial desempenhar essa função e deixar de realizar a prisão em flagrante quando presente alguma das excludentes de ilicitude.

Todavia, é de se notar que tal restrição imposta à autoridade policial somente se aplica quando se fala do auto de prisão em flagrante. Durante a atuação no inquérito policial, por exemplo, nada obsta o reconhecimento de circunstâncias excludentes por parte do delegado de polícia, que pode decidir pelo não indiciamento do investigado ao concluir a apuração do delito (ANDREOTTI, 2008).

Atualmente, prevalece o entendimento de que as referidas atribuições seriam vedadas ao Delegado de Polícia. Assim, a deliberação acerca das excludentes de ilicitude e do princípio da insignificância seria de competência exclusiva da autoridade judicial.

Nesse sentido, Nucci afirma que:

Confirmando o fato de a autoridade policial dever lavrar, sempre, o auto de prisão em flagrante, tão logo tome conhecimento da detenção ocorrida, realizando apenas o juízo de tipicidade, sem adentrar as demais excludentes do crime, cabe ao magistrado, recebendo a cópia do flagrante, deliberar sobre a liberdade provisória, que é um direito do indiciado, desde que preencha os requisitos legais. Nesse caso, quando houver nítida impressão ao juiz de que o preso agiu em estado de necessidade, legitima defesa, exercício regular do direito ou estrito cumprimento do dever legal, deve permitir que aguarde o seu julgamento em liberdade, não tendo o menor sentido em matelo preso (NUCCI, 2008, p. 611).

Do trecho acima colacionado, vê-se que NUCCI (2008) se filia à corrente doutrinária que limita a atuação do delegado de polícia ao juízo de tipicidade do fato, sendo-lhe vedada a análise das causas 
excludentes de ilicitude, uma vez que este seria o papel do magistrado. Desse mesmo entendimento, compartilham Lima (2013) e Choukr (2014).

MORAES (2015, p. 06) lembra que esse entendimento não é unânime. Vasta parte da doutrina reconhece a legitimidade da valoração das excludentes de ilicitude pelo Delegado de Polícia. Capez (2014, p. 334) leciona que "evidentemente, a autoridade policial não precisa prender em flagrante vitima de estupro ou roubo que, claramente, em situação de legítima defesa, matou seu agressor".

Segundo o Autor, seria mais acertado o entendimento que deve ser atribuída ao Delegado de Polícia a possibilidade de deliberação acerca da presença ou não de circunstâncias que excluam a ilicitude do fato.

Neste sentido, MORAES (2015, p. 06):

Não haveria qualquer lógica em um ordenamento que a Constituição impõe como valor máximo a dignidade da pessoa humana, em que qualquer medida restritiva da liberdade deve ser vista como exceção que uma pessoa seja presa quando está praticando uma conduta amparada por uma causa justificante que afasta a ilicitude dessa conduta.

O citado Autor ainda nos recorda que o Código de Processo Penal data de 1941, elaborado durante a vigência de um regime de inspiração facista, ao passo que a atual Constituição Federal traduz o retorno do Estado Democrático de Direito, com forte apreço pelo respeito aos direitos humanos.

Compartilhando do mesmo entendimento, temos LOPES JÚNIOR e GLOECKNER (2014, p.56):

[...] no atual estágio do desenvolvimento processual penal brasileiro, os princípios constitucionais emergem como verdadeiros filtros de controle sobre as normas (na maioria das vezes, regras) infraconstitucionais, mormente aquelas disciplinadas pelo Código de Processo Penal brasileiro, verdadeiro monumento facista [...].

A Constituição Federal traz como corolário o princípio da dignidade da pessoa humana, o qual reúne todos os direitos fundamentais, colocando o ser humano como centro do ordenamento jurídico, o fim que justifica e dá legitimdade ao Estado (MORAES, 2015). Neste diapasão, o mesmo diploma legal traz ainda também o direito à liberdade, estampado no inciso LXI, do artigo $5^{\circ}$, da Constituição da Republica "ninguém será preso senão em flagrante delito ou por ordem escrita e fundamentada de autoridade judiciária competente, salvo nos casos de transgressão militar ou crime propriamente militar, definido em lei" (BRASIL, 1988).

Na mesma linha de pensamento, OLIVEIRA (2014) frisa que atribuir essa competência à Autoridade Policial seria assegurar garantias individuais, respeitar o princípio da dignidade da pessoa humana e evitar prisões dispensáveis, o que não ocorre em se fazendo uma interpretação e aplicação literal do artigo 310, parágrafo único, do Código de Processo Penal.

Importante destacar que a Constituição Federal não traz o termo delito numa definição leiga. Ao se referir a delito, o Texto Constitucional faz menção à teoria do crime. MORAES (2015, p. 08) assevera que "a Constituição condicionou a existência do flagrante ao "delito" justamente para impor uma garantia ao acusado no momento da captura por um fato aparentemente delituoso".
Portanto, é indispensável a existência do delito para configuração do flagrante e, por conseguinte, para legitimar a prisão. Em outras palavras, não há como existir uma prisão em flagrante consitucional sem a prática anterior de um delito. Deste modo, no momento da prisão devem ser aferidos os elementos caracterizadores do crime de forma positiva (sua presença) e de forma negativa (a existência de causas excludentes) pela autoridade que lavra o auto de prisão em flagrante, ou seja, o Delegado de Polícia.

Neste contexto, questiona-se como a Autoridade Policial pode lavrar o auto de prisão em flagrante quando ausente um ou mais dos elementos caracterizadores do crime, tendo em vista que não se pode falar em prisão sem a prática pretérita de um crime.

Segundo ensinamento de OLIVEIRA (2014), o Delegado de Polícia somente deve lavrar o auto de prisão em flagrante delito quando ocorrer um crime, ou seja, conforme a teoria tripartida finalista, quando houver a prática de um fato típico, antijurídico e culpável.

Concordando o mesmo ponto de vista que leciona GOMES (2011, n.p.):

A verdade é que o Delegado de Polícia - autoridade com poder discricionário de decisões processuais - analisa se houve crime ou não quando decidir pela lavratura do Auto de Prisão. E ele não analisa apenas a tipicidade, mas também a ilicitude do fato. Se o fato não viola a lei, mas ao contrário, é permitida por ela (art. 23 do $\mathrm{CP}$ ) não há crime e, portanto, não há situação de flagrante. Não pode haver situação de flagrante de um crime que não existe (considerando-se os elementos de informação existentes no momento da decisão da autoridade policial). O Delegado de Polícia analisa o fato por inteiro. A di- 
visão analítica do crime em fato típico, ilicitude e culpabilidade existe apenas por questões didáticas. Ao Delegado de Polícia cabe decidir se houve crime ou não. E o art. 23, I a III, em letras garrafais, diz que não crime em situações de excludentes de ilicitude.

Assim, se ausentes quaisquer dos elementos do crime, o flagrante não deve ser autuado, o que nos leva a compreender que o Delegado deve realizar uma análise das excludentes de antijuridicidade e ponderar sobre a insignificância do fato.

Da interpretação do artigo 310, parágrafo único, do Código de Processo Penal, OLIVEIRA (2014) observa uma omissão por parte do legislador, que não traz vedação nem permissão expressa, contribuindo para a persistência do embate, o qual, para o Autor, deveria ter como solução a atribuição ao Delegado de deliberar acerca da existência de circunstância excludente ou de insignificância na prática de um fato.

Isso se justifica porque não há como cogitar um Estado Democrático de Direito onde o Delegado de Polícia não possa apreciar se os dados que formam o conceito de crime estão visíveis, vez que, agindo de maneira contrária implicaria em ofensa aos princípios e garantias constitucionais.

Imperioso destacar que a emenda constitucional $n^{\circ} 35 / 2012$, $\S \S 2^{\circ}$ e $3^{\circ}$ fez algumas alterações na Constituição Federal alusivas a este contexto:

Emenda Constitucional $\mathrm{n}^{\mathrm{o}} 35$, de 3 de abril de 2012 - A mesa da assembleia legislativa do estado de São Paulo, nos termos do $\S 3^{\circ}$ do artigo 22 da Constituição do Estado, promulga a seguinte emenda ao texto constitucional:

$\S 2^{\circ}$ - No desempenho da atividade de Polícia Judiciária, instrumental à propositura de ações penais, a Polícia Civil exerce atribuição essencial a função jurisdicional do Estado e à defesa da ordem jurídica.

$\S 3^{\circ}$-Aos Delegados de Polícia é assegurado a Independência Funcional pela livre convicção nos atos da Polícia Judiciária (BRASIL, 2012).

Para dar maior ênfase e força à Autoridade Policial no que diz respeito a atuação, a Lei 12.830/2013 no art. $2^{\circ}$ $\S 6^{\circ}$ defende que:

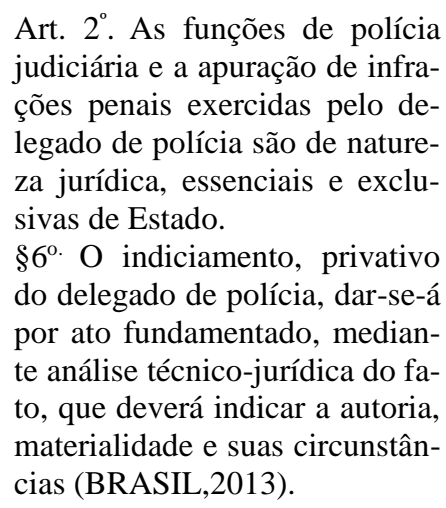

Como se nota dessas alterações, foi garantida à ao Delegado de Polícia a livre convicção nos atos da Polícia e reafirmada a essencialidade das funções exercidas pela polícia judiciária, principalmente no que se refere às atribuições da Autoridade Policial. Isso demonstra a preservação pela Constituição da importância dos atos de polícia também quando das prisões em flagrante, tendo em vista que estas representam uma forte limitação a um dos maiores direitos fundamentais mais importantes esculpidos na Constituição Federal de 1988, qual seja, o direito à liberdade.

\section{A INDEPENDÊNCIA FUNCIO- NAL DO DELEGADO DE POLÍ- CIA FACE A PROPOSTA DE EMENDA À CONSTITUIÇÃO No 293/2008}

A proposta de emenda à Constituição no 293/2008, de autoria do Deputado Alexandre Silveira (PPS/MG), modifica a redação do art. 144 , da
Constituição Federal, com o escopo de conceder independência funcional aos Delegados de Polícia. Atualmente, encontra-se pronta para pauta na $\mathrm{Co}$ missão de Constituição e Justiça e de Cidadania (CCJC).

Nesse sentido, o texto da proposta:

Art. 144 - $§ 10$. O delegado de polícia de carreira, de natureza jurídica, exerce função indispensável à administração da justiça, sendo-lhe assegurada independência funcional no exercício do cargo, além das seguintes garantias: a) vitaliciedade, não podendo perder o cargo senão por sentença judicial transitada em julgado;

b) inamovibilidade, salvo por motivo de interesse público; e

c) irredutibilidade de subsídio (BRASIL, 2008).

A referida proposta atribui às Autoridades policiais independência funcional no exercício do cargo, por meio das garantias da vitaliciedade, inamovibilidade e irredutibilidade de subsídios.

A vitaliciedade é a garantia que certifica ao servidor o direito de só ser demitido do respectivo cargo por decisão judicial transitada em julgado. Sendo assim, o funcionário público não pode ser demitido por mediação de simples processo administrativo disciplinar. A inamovibilidade incide na impossibilidade de remoção do funcionário de um cargo para outro, exceto por interesse público. Finalmente, a irredutibilidade de subsídio significa que o funcionário não pode ter seus vencimentos reduzidos (BARROS FILHO, 2011).

A Doutrina e Jurisprudência afirmam que a independência é dos membros da instituição, isto é, existindo a Autoridade Policial, a independência no exercício de suas funções 
não estará hierarquicamente subordinada a qualquer outra autoridade, seja externa ou do próprio órgão policial, ou seja, as denominadas garantias institucionais são prerrogativas que visam defender a independência do próprio órgão (LOPES JUNIOR, 2001).

Neste significado:

Em verdade, a independência funcional é um sério limite à Administração, porque, em princípio, esta não pode ditar aos membros da Instituição o modo, o momento, o conteúdo ou a qualidade do ato funcional o que praticamente elimina a ideia de hierarquia (LOPES JÚNIOR, 2001 p. 39).

Essa independência assegurará aos Delegados de Polícia cumprir melhor seu ofício:

[...] sem o receio de represálias tanto de dos agentes investidos de poder político (notadamente do poder executivo) quantos de particulares (especialmente as pessoas dotadas de poderio econômico, como, por exemplo, as grandes corporações, cujos interesses a Instituição é suscetível de contrariar) (LOPES JUNIOR, 2001 p. 41)

Dissertando acerca da importância da atividade policial, TOURINHO FILHO (2010, p. 284) leciona que:

Há uma séria crítica à Polícia no sentido de poder sofrer pressão do Executivo ou mesmo de seus superiores e de políticos. É comum, em cidades do interior, a Autoridade Policial ficar receosa de tomar alguma medida que possa contrariar Prefeitos e Vereadores. Nesses casos, é o Ministério Público, então, que toma a iniciativa. Mas, para que se evitem situações como essas, bastaria conferir aos Delegados de Polícia, que têm, repetimos, a mesma formação jurídica dos membros do Ministério Público e Magistratura e, ao contrário destes, diuturnamente expõem suas vidas no desempenho de suas árduas tarefas, as mesmas garantias conferidas àqueles; irredutibilidade de vencimentos, inamovibilidade (salvo o caso de interesse público devidamente apurado) e vitaliciedade.

Ademais, o Deputado REGIS DE OLIVEIRA (PSC/SP), enquanto relator da Proposta de Emenda à Constituição Federal no. 412, de 2009, que altera o $\S 1^{\circ}$, artigo 144 , da Constituição Federal, dispondo sobre a organização da Polícia Federal, ao tratar do entendimento doutrinário sobre a autonomia da Polícia Judiciária cita os professores LUIZ FLÁVIO GOMES E FÁBIO SCLIAR:

A preocupação com a ausência de autonomia da Polícia Judiciária é justificável em função da crescente importância que a investigação criminal vem assumindo em nossa ordem jurídica, seja por conta de uma necessária mudança de postura a seu respeito, para considerá-la como uma garantia do cidadão contra imputações levianas ou açodadas em juízo, seja pelo papel mais ativo que tem sido desempenhado nos últimos tempos pelos órgãos policiais (GOMES; SCLIAR; 2008 apud BRASIL, 2009, p. 6).

Marques (2000, p. 176) conclui que "a polícia judiciária precisa ser aparelhada para tão alta missão, tanto mais que o Código de Processo Penal a prevê expressamente no art. $6^{\circ}$, inciso IX”. O autor afirma que é preciso uma reforma que separe a polícia judiciária da polícia de segurança e da polícia política, reorganizando a polícia judiciária em quadros próprios e lhe cercando de "garantias que a afastem das influências e injunções de ordem partidária, a polícia judiciária, que é das peças mais importantes e fundamentais da justiça penal, estará apta para tão alta e difícil tarefa" (MARQUES, 2000, p. 176).

Por tudo quanto o exposto, é preciso reconhecer que há dentro do ordenamento jurídico uma vaga exposição sobre a garantia aos delegados de polícia a independência funcional, o que dificulta a atuação autônoma da Autoridade Policial. Deste modo, a referida lacuna deve ser preenchida, possibilitando que o Delegado de Polícia desempenhe suas acentuadas funções livre de influência política.

\section{CONSIDERAÇÕES FINAIS}

O presente estudo foi construído com base na análise da possibilidade de o primeiro juízo da tipicidade penal do fato ser realizado pela autoridade policial, além da reflexão a respeito de sua independência funcional.

As controvérsias jurídicointerpretativas acerca da matéria e a verificação da necessidade de se conferir uma maior independência funcional ao Delegado de Polícia, bem como as implicações jurídicas decorrentes disso justificaram a importância do trabalho para âmbito jurídico.

Diante dos objetivos previamente definidos e da aplicação da presente pesquisa, observou-se, inicialmente, a prevalência, não unânime, de um entendimento que preza pela impossibilidade jurídica da aplicação das excludentes de antijuridicidade pelo Delegado de Polícia quando da autuação da prisão em flagrante.

Todavia, há corrente doutrinária crescente em sentido contrário, que prima pela plausibilidade de tal atribuição ser conferida à Autoridade Policial, com vistas a impedir violações ao direito à liberdade do indivíduo. 
No que tange ao problema formulado no projeto de pesquisa, o estudo evidenciou que seria mais acertado o entendimento segundo o qual deve ser atribuída ao Delegado de Polícia a possibilidade de deliberação acerca da presença ou não de circunstâncias que excluam a ilicitude do fato, isso porque a atual Constituição Federal traduz o retorno do Estado Democrático de Direito, com forte apreço pelo respeito aos direitos humanos, especialmente o direito à liberdade.

Revelou-se, ainda, a necessidade de conferência de garantias e maior independência à Autoridade Policial, como aquelas enumeradas na Proposta de Emenda Constitucional 293/2008, a qual atribui aos Delegados de Polícia a independência funcional no exercício do cargo, por meio das garantias da vitaliciedade, inamovibilidade e irredutibilidade de subsídios.

Por fim, cumpre salientar que um ordenamento jurídico coerente com o Estado Democrático de Direito proposto pela Constituição Federal deve primar por maior agilidade $\mathrm{e}$ eficiência na verificação jurídica de condutas possivelmente típicas, de modo a evitar desrespeito a direitos e garantias fundamentais em situações de clara inexistência de antijuridicidade.

\section{REFERÊNCIAS}

ALMEIDA, L. M. M. A Autoridade Policial e o Princípio da Insignificância. E-Locução. Revista Científica da FAEX. Disponível em: $<$ periodicos.faex.edu.br/index.php/elocucao/article/download/2/3>.

ANDREOTTI, A. T. H. Reconhecimento das excludentes de antijuridicidade pela autoridade policial no auto de prisão em flagrante delito. 138 p. Dissertação (Mestrado em Direito) - Centro Universitário Toledo UNITOLEDO, 2008.

BARROS FILHO, M. L. Independência funcional dos delegados de polícia. Revista Jus Navigandi, Teresina, ano 16, n. 2966, 15 ago. 2011. Disponível em:

<https://jus.com.br/artigos/19745>. Acesso em: 7 nov. 2016.

BRASIL. Carta de 26 de Outubro de 1829. Acesso em 20 de outubro de 2017. Disponível em:

<http://bd.camara.gov.br/bd/bitstream/ han-

dle/bdcamara/18352/colleccao_leis_18 29_parte1.pdf>.

BRASIL. Constituição da República Federativa do Brasil de 1988. Diário Oficial da União, Brasília, 05 de outubro de 1988. Disponível em:

$<w w w . p l a n a l t o . g o v . b r / c c i v i l \_03 / C o n s t$ ituicao/Constituicao.htm>. Acesso em: 29 agosto 2017.

BRASIL. Decreto-Lei, de 3 de outubro de 1941. Código de Processo Penal. Disponível em:

<http://www.planalto.gov.br/ccivil_03/ decretolei/Del3689Compilado.htm Acesso em 01 outubro de 2017.

BRASIL. Lei $\mathbf{n}^{\circ}$ 12.830, de 20 de junho de 2013. Dispõe sobre a investigação criminal conduzida pelo delegado de polícia. Disponível em: <http://www.planalto.gov.br/ccivil_03/ ato2011-2014/2013/lei/112830.htm>. Acesso em: 09 de novembro de 2017.

\section{BRASIL. Proposta de Emenda à}

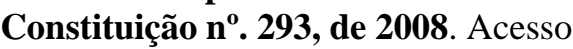
em 01 novembro de 2017. Disponível em:

<http://www.camara.gov.br/proposico esWeb/fichadetramitacao?idProposica $\mathrm{o}=409032$.

BRASIL. Proposta de Emenda à

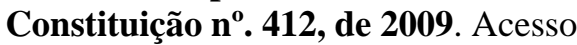
em 09 novembro de 2017. Disponível em:

<http://www.camara.gov.br/sileg/integ ras/712779.pdf $>$.
CHOUKR, F. H. Código de Processo Penal: comentários consolidados e crítica jurisprudencial. 6. ed. São Paulo: Saraiva, 2014.

GOMES, L. F., SCLIAR, F. Investigação preliminar, polícia judiciária e autonomia. Disponível em:

<https://www3.lfg.com.br/public_html /article.php?story=2008102015414567 2>. Acesso em 20 de outubro de 2017.

LAKATOS, E. M.; MARCONI, M. A. Metodologia do trabalho científico. $5^{\mathrm{a}}$ ed. São Paulo: Editora Atlas, 2003.

LIMA, R.B. de. Curso de processo penal. Niterói: Impetus, 2013. p. 896.

LOPES JÚNIOR, A.; GLOECKNER, R.J. Investigação preliminar no processo penal. 6.ed. São Paulo: Saraiva, 2014.

\section{LOPES JÚNIOR, A. Sistemas de} Investigação Preliminar no Processo Penal. Rio de Janeiro: Lumem Juris, 2001.

MARQUES, J. F. Elementos de Direito Processual Penal. Campinas: Millenium. 2a Ed. 2000.

MORAES, V.M. O Delegado de Polícia como primeiro fiscal do exercício punitivo do Estado através da análise do conceito analítico de crime. Disponível em:

$<$ http://www.emerj.tjrj.jus.br/paginas/t raba-

lhos_conclusao/1 semestre2015/pdf/Vi niciusMirandadeMoraes.pdf >. Acesso em 24 de outubro de 2017.

\section{NUCCI, G.S. Manual de Direito}

Penal. Parte Geral. São Paulo: Editora Revista dos Tribunais, 6 ed. 2008.

NUCCI, Guilherme de Souza. Código de Processo Penal Comentado. São Paulo: Revista dos Tribunais, 2002.

SIMÕES, A. G. O crime de plágio e suas variações no ambiente acadêmico. In: Âmbito Jurídico, Rio Grande, XV, 
n. 96, jan 2012. Disponível em:

<http://www.ambito-

juridico.com.br/site/index.php?n_link= revista_artigos_leitura\&artigo_id=110 57>. Acesso em dez 2017.

OLIVEIRA, S. M. C. de. Competência do Delegado de Polícia para Realizar Análise das Excludentes do

Crime. Escola da Magistratura do

Estado do Rio de Janeiro, 2014. Acesso em 12 de setembro de 2017. Disponível em: <

http://www.emerj.rj.gov.br/paginas/tra ba-

lhos_conclusao/1semestre2014/trabalh os_12014/SorayaMuniz.pdf>.

TOURINHO FILHO, F. C. Processo

Penal. 32 ${ }^{\mathrm{a}}$ Ed. São Paulo: Saraiva

2010. 